\title{
NOTAS SOBRE A DESIGUALDADE SOCIAL NO BICO DO PAPAGAIO $^{1}$ - TOCANTINS ${ }^{2}$
}

\author{
NOTES ON SOCIAL INEQUALITY OF THE BICO DO PAPAGAIO IN THE \\ STATE OF TOCANTINS - BRAZIL
}

Nilton Marques de Oliveira

Universidade Federal do Tocantins - UFT

Udo Strassburg

Universidade Estadual do Oeste do Paraná - UNIOESTE

\section{RESUMO}

O objetivo central desse artigo foi caracterizar a pobreza e os indicadores de desenvolvimento socioeconômicos da Microrregião do Bico do Papagaio (Tocantins), tendo como referencial teórico a Abordagem da Capacitação (AC), de Amartya Sen. Os principais indicadores utilizados foram: índice de natalidade, índice de mortalidade bruta e infantil, Índice de Desenvolvimento Humano, taxa de alfabetização, taxa de fecundidade, Produto Interno Bruto - (PIB) per capita. Os dados foram coletados no Instituto Brasileiro de Geografia e Estatística (IBGE), Governo do Estado do Tocantins e no Programa das Nações Unidas para o Desenvolvimento (PNUD). Os resultados sugerem que na Microrregião do Bico do Papagaio há indicação de queda da pobreza extrema, com tendência na redução de desigualdade de renda. Apesar do avanço dos indicadores, a Microrregião tem um longo caminho a percorrer para chegar ao padrão satisfatório de desenvolvimento humano, social e econômico.

Palavras-chave: Capacitações; Políticas Públicas; Bico do Papagaio

\begin{abstract}
The main objective of this paper is to characterize poverty and indicators of socioeconomic development of the micro region of the Bico do Papagaio in the State of Tocantins, Brazil, as theoretical referential Capability Approach (CA), from Amartya Sen. The main indicators used were: the birth rate, crude rate infant mortality, the human development index, literacy rate, fertility rate, the Gross Domestic Product - (GDP) per capita. The data were collected in the Brazilian Institute of Geography and Statistics (IBGE), the State of Tocantins and the United Nations Development Program (UNDP). The results suggest that the micro region of the Parrot's Beak have evidence of decline in extreme poverty and with a tendency to reduce income inequality. Despite the micro region indicators progress, it has a long way to go to achieve a satisfactory level of human, social and economic development.
\end{abstract}

\footnotetext{
${ }^{1}$ Embora o Bico do Papagaio denomine a área do Interflúvio Araguaia-Tocantins, localizada na porção setentrional do território tocantinense, ela compreende ainda o sudoeste do Maranhão até o sudeste do Pará, a que a denominação Bico do Papagaio comumente se reporta. Neste estudo, a análise recai apenas na Microrregião do Tocantins.

${ }^{2}$ A primeira versão deste artigo foi apresento no $12^{\text {th }}$ Congress of the Brazilian Regional Science Association XII EANBER, and $2^{\text {nd }}$ Ibero-Americaan Congress on Regional Development entre 15 e 17 de outubro de 2014, no Cedeplar, UFMG, Belo Horizonte, Brazil.
} 
Keywords: Capabilities; Public Policy; Parrot's Beak

Recebido em 09/07/2014. Aceito em 27/09/2014. Publicado em 14/01/2015.

\section{INTRODUÇÃO}

O presente artigo tem por objetivo de caracterizar a pobreza e os indicadores de desenvolvimento humano, social e econômico, numa região periférica do Estado do Tocantins: a Microrregião do Bico do Papagaio. Uma região de extrema pobreza, com grandes desigualdades sociais e econômicas, e que, para completar, foi palco de enormes conflitos agrários nas décadas de 1970 e 1980.

No Tocantins, a pobreza é extrema, o estado tem um dos piores indicadores socioeconômicos do país. Esse problema persiste de forma secular. O universo da pobreza no estado vem desde a sua estrutura socioeconômica baseada na exploração da mineração no século XVIII até os dias atuais. Os últimos resultados do censo (IBGE, 2010) mostram que o Brasil tem 16,2 milhões de brasileiros que vivem em extrema pobreza, o equivalente a 8,5\% da população. No Tocantins, esse percentual chega a 11,8\% da sua população vivendo em extrema pobreza, são cerca de 163 mil de um total de 1.383,4 mil habitantes.

Dos mais de 163 mil pobres do estado, 48,5\% estão na área rural e 51,4\% na área urbana. A pesquisa mostrou que $12,8 \%$ dos tocantinenses vivem com renda mensal per capita de até um quarto do salário mínimo, ou seja, menos de R \$ 127,50 por pessoa. São 398.367 domicílios nessas condições (considerando 3,3 pessoas por domicílios). Outros 21.979 (5,5\% do total) domicílios não têm rendimentos. Ampliando-se a análise, chega-se a verificar que mais de 72,5\% (1.033.412) da população do estado sobrevive com renda de até um salário mínimo, $\mathrm{R} \$ 510,00$ por mês, considerando a média de 3,3 pessoas por domicílios.

Fazendo uma análise dos indicadores socioeconômicos do estado, tendo por base o ano de 2008, o Tocantins apresenta um PIB per capita de $\mathrm{R} \$ 10.233$; uma expectativa de vida ao nascer de 71,6 anos, uma taxa de analfabetismo de 14,8\%; mortalidade infantil de 26,4\% de cada mil nascido vivo; IDH de 0,756 , ficando na posição de $15^{\circ}$ dos estados da federação, a região Norte com IDH de 0,764. O Brasil, com IDH de 0,699, ocupa o $73^{\circ}$ lugar na classificação mundial. A cada ano o país tem conseguido elevar seu IDH, e fatores como o aumento da expectativa de vida e taxa de alfabetização estão diretamente associados a este progresso. Entretanto, existem grandes disparidades sociais e econômicas no Brasil. As 
diferenças regionais são grandes, o país apresenta realidades distintas em seu território. As médias de IDH mais elevados estão nas regiões Sul e Sudeste, enquanto as regiões Norte e Nordeste apresentam médias baixas (PNUD, 2008).

Diante dessas considerações, fazer uma investigação sobre a pobreza no estado, mais especificamente na Microrregião do Bico do Papagaio, é mais que oportuno. Assim sendo, este trabalho se justifica pelo fato de a Microrregião do Bico do Papagaio ter sido objeto de estudo por diferentes áreas do saber no que se refere aos conflitos e à luta pela posse de terra, no entanto, poucos estudos têm apresentado e discutido os indicadores sociais, populacionais e econômicos na região, trazendo, assim, uma nova contribuição pra o debate nessa localidade.

Marcada pela pobreza, pela agricultura de subsistência, pela ausência de serviços básicos de infraestrutura, saúde e educação, a região, como dito, é campo fértil para estudar as relações sociais, políticas, econômicas e de poder que os atores sociais vêm exercendo há mais de 130 anos entre os Apinagés e Gavião, atraídos pelos recursos minerais e extrativistas, até os programas de desenvolvimento rural integrado implementados pelo Governo Federal por meio do Programa Nacional de Fortalecimento da Agricultura Familiar nos anos 90 (ARAGÓN, 1981). Como se vê, desde outrora esse espaço já era marcado por conflitos e disputas pelos recursos naturais.

A hipótese central deste projeto é que a utilização de uma abordagem multidimensional para analisar a pobreza e os indicadores sociais e econômicos no Tocantins e na Microrregião do Bico do papagaio permitirá a identificação de diferentes olhares associados à pobreza, possibilitando uma melhor compreensão da complexidade do tema.

Os estudos realizados para analisar a pobreza datam do início do século XIX e apresentam diferenças conceituais e metodológicas importantes. Ainda hoje, não há uma definição consensual sobre o que é a pobreza, suas causas e seu tamanho. E dificilmente haverá, pois se trata de teia que envolve questões sociais, econômicas, culturais, políticas e morais. O que se percebe, no entanto, é que há um direcionamento para uma definição mais abrangente e multidimensional da pobreza.

A pobreza, por apresentar um caráter multidimensional, torna-se, portanto, de difícil mensuração. Se o problema de um é a insuficiência de renda, o do outro está na habitação inadequada, o do outro na falta de saúde e o do outro pode estar na privação de sua liberdade. Nesse caso, quem é o mais pobre? Como classificá-los? 
Não existe uma fórmula única para a construção de indicadores escalares de pobreza multidimensional. Perguntas surgem na sua construção tais como: Quais devem ser as variáveis adotadas e seus pesos? Quais as dimensões mais relevantes? Qual deve ser a técnica de agregação das dimensões da pobreza? Como agregar a pobreza de todas as pessoas? As repostas a esses questionamentos ficam por conta de cada pesquisador para encontrar as melhores soluções. Isso mostra a complexidade de analisar e caracterizar a pobreza com enfoque multidimensional.

A Abordagem da Capacitação (AC) ainda é pouco explorada e difundida no Brasil, entretanto, ela se constitui numa abordagem ampla, rica e abrangente, que evita erros muito comuns na abordagem baseada no utilitarismo (unidimensional), que tem fundamentado as ações de organizações internacionais de desenvolvimento, tais como o PNUD e o Banco Mundial. A AC teve início com o indiano professor Amartya Sen (Nobel em 1998), logo depois vem a contribuição de Marta Nussbaun, que, juntamente com Sen, passou a desenvolver pesquisas com enfoque nessa abordagem.

A AC tem sido utilizada em diferentes áreas do conhecimento, que vão desde a sociologia, economia, saúde, política, e apresenta um estudo multidisciplinar por tratar das nossas capacitações, das nossas potencialidades, ou seja, o que realmente podemos fazer, ser e ter.

Destarte, é relevante o estudo sobre esse tema, que pode evidenciar se o Governo Federal e o Estadual estão investindo em melhoria da qualidade de vida por meio de políticas públicas, transferência de renda, projetos e financiamento da agricultura familiar, educação e saúde.

Isso posto, este artigo está divido em quatro partes, além desta introdução. A seção 2 descreve os procedimentos metodológicos, a seção 3 apresenta e analisa os indicadores sociais, populacionais e econômicos. E as considerações finais sumarizam o trabalho.

\section{REFERENCIAL TEÓRICO E PROCEDIMENTOS METODOLÓGICOS}

\subsection{Abordagem Unidimensional}

Nesta parte, serão descritas sumariamente algumas considerações sobre a Abordagem Unidimensional e a Abordagem da Capacitação (AC), tendo como expoente principal Amartya Sen (2000, 2008a, 2008b). 
A análise da medida unidimensional está fundamentada na abordagem da pobreza como subsistência e na abordagem monetária da pobreza. As primeiras pesquisas sobre a pobreza (séculos XIX e XX) se fundamentavam na sua definição associada à ideia de subsistência. O conceito de subsistência era fundamentado nas necessidades nutricionais mínimas, suficientes para a manutenção e a sobrevivência do indivíduo e da sua família.

O trabalho pioneiro citado na literatura é de Rowntree, que estudou a pobreza na cidade de York em 1901, Sen (1983), Rocha (2003), Machado (2006). Rowntree definiu famílias em pobreza primária como aquelas cujo total de rendimentos eram insuficientes para satisfazer suas necessidades básicas e garantir a "manutenção da eficiência física".

A pobreza vista como insuficiência nutricional exerceu influência nas políticas econômicas do século XX. Segundo Codes (2008:12), essa ideia ainda permanece, influenciando políticas de assistência à pobreza em vários países do mundo.

Essa abordagem fundamentada na subsistência proporcionou o desenvolvimento da análise da pobreza com foco na insuficiência de renda. A análise da pobreza sob a perspectiva da renda foi também incentivada pela intensificação das atividades capitalistas, em que parcela ponderável das necessidades das pessoas é obtida por meio de trocas mercantis, sendo natural que o atendimento a essas necessidades seja feito de forma indireta, via renda (ROCHA, 2003:12).

Esse olhar da pobreza com enfoque monetário tem por base a Teoria Econômica Neoclássica, sendo fundamentada no pensamento utilitarista, ou seja, "a utilidade de uma pessoa é representada por alguma medida de seu prazer ou felicidade" (SEN, 2000:77), implicando uma noção de valor com base somente na utilidade individual, definida em termos subjetivos (SEN, 2008:94).

Dessa forma, o bem-estar individual é definido com base na sua função consumo e, por extensão, o bem-estar social é a maximização da soma das utilidades, ou a função consumo total. É dessa maneira que a renda, ou consumo, aparece como indicador exclusivo de bem-estar. A pobreza é entendida como uma insuficiência de renda (consumo) que impede o indivíduo de alcançar um nível mínimo de bem-estar que maximiza a utilidade total (LACERDA, 2009).

No início dos anos 70, as limitações, os questionamentos da medida unidimensional na análise da pobreza aumentaram, e isso fez com que alguns estudiosos sobre o assunto encontrassem formas alternativas de analisá-la. 
Na concepção de Lacerda (2009), esse movimento se intensificou, permitindo que o enfoque multidimensional da pobreza ganhasse força no debate, embora a abordagem monetária ainda domine. No estudo multidimensional da pobreza, duas abordagens têm se destacado: a abordagem das necessidades básicas e a abordagem da capacitação (AC).

A perspectiva multidimensional se caracteriza por uma "visão humanista que vai além da economia para se remeter à moral e ao desenvolvimento humano em toda sua dimensão, inclusive de liberdade e de dignidade" (SEN, 2000). Essa perspectiva refuta o argumento de que o crescimento econômico é condição suficiente para reduzir e ou erradicar a pobreza, garantindo a maximização do nível de bem-estar da sociedade.

\subsubsection{Abordagem da Capacitação (AC)}

A Abordagem da Capacitação (Capability Approach) vem sendo desenvolvida desde a década de 70 por Amartya Sen e Martha Nussbaum. A perspectiva dessa abordagem não se restringe apenas à análise da pobreza, trazendo contribuições importantes para a Teoria do Bem-Estar Social e para a Teoria do Desenvolvimento Socioeconômico, particularmente, porque analisa o desenvolvimento ancorado no princípio da igualdade e da liberdade substantiva.

O bem-estar da sociedade deve ser avaliado segundo as liberdades desfrutadas por seus membros. A liberdade é o "determinante principal da iniciativa individual e da eficácia social" (SEN, 2000:33). A liberdade é o "fim primordial e o principal meio do desenvolvimento" (SEN, 2000:52). Entre estas liberdades, estão a liberdade política, a facilidade econômica, as oportunidades sociais, as garantias de transparência e a segurança protetora.

$\mathrm{Na}$ AC, a pobreza vista por Sen (2000) deve ser entendida como privação de capacitações básicas. Essa abordagem está relacionada com o conceito de desenvolvimento humano. Na perspectiva de Comim et al. (2006), a pobreza representa a ausência de algumas capacitações básicas para funcionar, ou seja, a carência pessoal de oportunidades para realizar alguns níveis minimamente aceitáveis de funcionamentos. Os funcionamentos relevantes podem variar dos físicos, como estar bem nutrido, estar adequadamente vestido e abrigado e evitar morbidez que pode ser prevenida, às realizações sociais mais complexas, como participar da vida em comunidade. 
Para Comim et al. (2006:7), o principal aporte teórico da Abordagem da Capacitação (AC) como um framework normativo amplo é justamente expandir o espaço informacional ao nível dos funcionamentos e das capacitações, ou seja, da liberdade substantiva (capacitação) de uma pessoa para escolher uma vida que ela tem razão para valorizar por meio dos seus estados e ações (funcionamentos realizados).

Essa perspectiva ampla possibilita que ela possa ser utilizada em vários campos de pesquisa, como pobreza, desigualdade, desenvolvimento, economia do bem-estar, filosofia política, justiça, arranjos sociais, padrões de vida e política social.

$\mathrm{Na}$ Abordagem da Capacitação (AC), funcionamentos e capacitações são seus principais elementos constituintes. O conceito de funcionamento reflete as várias coisas que uma pessoa pode considerar valiosa fazer e ser. Funcionamentos vão desde questões básicas como ter boa saúde até as mais complexas como ser feliz e ter respeito próprio (SEN, 2000; 2001).

A capacitação [capability], como destaca Sen $(2000 ; 2001)$, representa a liberdade substantiva em que uma pessoa pode realizar combinações alternativas de funcionamentos. Pode ser compreendido também como um conjunto de vetores de funcionamentos, indicando a liberdade da pessoa, ou seja, suas oportunidades reais para levar um tipo de vida ou outro. Sen (in COMIM et al., 2006) esclarece que “ a capacitação de uma pessoa depende de uma variedade de fatores, incluindo características pessoais e arranjos sociais. As capacitações [capabilities] são aqueles funcionamentos alternativos, ou seja, são estados ainda não executados efetivamente pela pessoa, mas são passíveis disto. Já o conjunto de capacitações [capabilities set] de um individuo pode ser considerado o conjunto de possibilidades que ele tem para levar a vida que deseja (SEN, 2000:95).

A Abordagem da Capacitação (AC) é, portanto, uma interação entre funcionamentos e capacitações, pois reconhece que, diante da complexidade do objeto de estudo e da diversidade entre as pessoas, limitar a análise apenas a um enfoque a afastaria da perspectiva da pobreza como privação de capacitações humanas.

Na concepção de Salama e Destremau (1999), utilizando o conceito de pobreza na visão seniana, diz-se que no enfoque das capacitações, nem as utilidades, nem o rendimento podem ser identificados com o bem-estar. A definição de pobreza não pode, portanto, se basear no fraco nível de um ou de outro, mas, de preferência, na inadequação dos meios 
econômicos referente à propensão das pessoas em convertê-las em capacitações de funcionar, isto num ambiente social, econômico e cultural particular.

Essa concepção de pobreza foi resumida por Sen (2000:110) em três argumentos favoráveis: concentração em privações intrinsecamente importantes, enquanto na abordagem monetária a concentração é naquilo que é importante instrumentalmente; reconhecimento de outras influências sobre a privação de capacitações e não unicamente a renda; e variabilidade da relação instrumental entre baixa renda e baixa capacitação entre comunidades, famílias e indivíduos.

Esse último argumento é considerado por ele o mais relevante para a avaliação da ação pública. A relação renda e capacitação pode ser afetada por diversos aspectos, tais como idade, papéis sexuais e sociais, localização e outras condições sobre as quais as pessoas não têm controle.

Percebe-se, com base nesses argumentos, que a adoção da perspectiva das capacitações na análise da pobreza desvia a atenção dos meios (renda) para os fins. Segundo Sen (2000:112), "as pessoas têm razão para buscar e, correspondentemente, para as liberdades de poder alcançar esses fins"

Essas duas perspectivas da pobreza, renda e capacitações, estão associadas. Um aumento de capacitação pode levar a um aumento de renda, contribuindo para a redução da pobreza por renda. Exemplos são os serviços sociais inclusivos que tendem a reduzir a privação de capacitações e, consequentemente, a produzir efeitos positivos na diminuição da pobreza monetária.

\section{2 Área de Estudo}

Nesta seção, é apresentada a área de estudo e suas características. Localizada no extremo norte do Estado do Tocantins, entre os estados do Pará e Maranhão, sua porção extrema é formada por dois rios, o Araguaia e o Tocantins, cujo formato da confluência, "bico", Figura 1, inspirou seu nome (SOARES, 2009).

Como dito, a área de objeto de estudo recai apenas no Estado do Tocantins, especificamente na Microrregião do Bico do Papagaio, com área de 15.993,20 km², correspondendo a $5,75 \%$ do território do Tocantins, sendo composta por 25 municípios $^{3}$. O

\footnotetext{
${ }^{3}$ Os 25 municípios que compõem a Microrregião são: Ananás, Angico, Araguatins, Augustinópolis, Axixá do Tocantins, Buriti, Carrasco Bonito, Darcinópolis, Esperantina, Itaguatins, Luzinópolis, Maurilândia, do
} 
Censo Populacional de 2010 registrou uma população de 196.367 habitantes, o que representa $14 \%$ do total do Estado. A densidade demográfica é de $12,45 \mathrm{hab} / \mathrm{km}^{2}$, enquanto a do estado é de 4,98hab/ $\mathrm{km}^{2}$ e a do Brasil, de 22,40 hab/ $\mathrm{km}^{2}$.

Segundo IBGE (2010), a Microrregião apresentou em 2010 a maior densidade demográfica do estado. No Tocantins, há uma grande dispersão da população, com algumas regiões populosas e outras não. A Figura 1 mostra a localização da Microrregião com seus respectivos municípios.

Durante as décadas de 1950 e 1960, com a construção de Brasília e o projeto de construção de grandes rodovias pelo Plano de Metas ${ }^{4}$, entre elas a rodovia Bélem-Brasília (BR-153) e a Transamazônica, esta Microrregião, assim como o norte goiano, passou por um processo de modificações na sua base produtiva, e o processo de migração se tornou mais pronunciado. Os programas de incentivos governamentais implantados nos anos 70, como o Polamazônia e o Polocentro, promoveram o aumento da fronteira econômica, acelerando o processo de modernização agrícola com a introdução de novas tecnologias.

Cabe destacar que a Microrregião do Bico do Papagaio foi palco dos maiores conflitos de terra do País ${ }^{5}$. No Tocantins, os conflitos agrários ocorreram nos municípios de Araguatins, Augustinópolis, Axixá, Buriti do Tocantins, Esperantina, Itaguatins, Praia Norte, Sampaio, São Miguel do Tocantins, São Sebastião do Tocantins e Sítio Novo do Tocantins (Figura 1).

Tocantins, Nazaré, Praia Norte, Riachinho, Sampaio, Santa Terezinha do Tocantins, São Bento do Tocantins, São Miguel do Tocantins, São Sebastião do Tocantins, Sítio Novo do Tocantins e Tocantinópolis.

${ }^{4}$ O Plano de Metas (1955) foi dividido em 30 metas, agrupadas em cinco setores: dos investimentos, 43,4\%; energia, 29,6\%; transportes, 3,2\%; alimentos, 20,4\%; indústria de base e educação, 4,3\%; além da construção de Brasília.Ver Abreu (1994).

${ }^{5}$ Para mais detalhes sobre esse conflitos agrários ocorridos no Bico do Papagaio, ver Soares(2009), Martins (1975 e 1997) 
Figura1 - Microrregião do Bico do Papagaio e seus respectivos municípios

Figure 1 - Bico do Papagaio of the micro-region and their municipalities

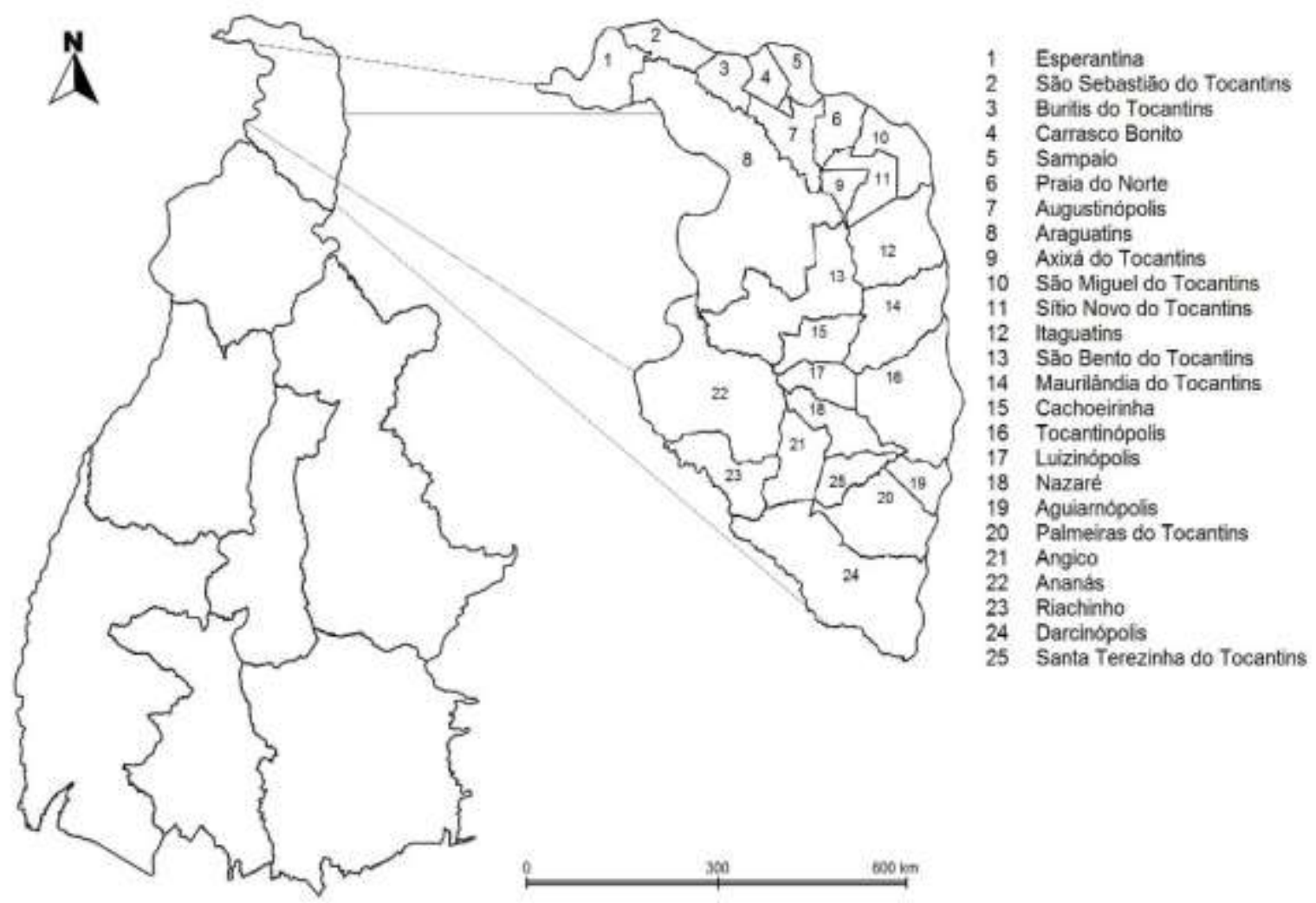

Fonte: Elaboração Própria.

Esses conflitos tiveram como gênese o processo de ocupação. $O$ primeiro foi espontâneo, agricultores nordestinos que, fugindo da seca e da grilagem em seus Estados, estabeleceram um sistema de roça de toco. O segundo, estimulado pelo Estado, teve como base a integração vertical com o mercado nacional e de exportações, cujos principais atores foram os grandes agropecuaristas do centro-sul do País (MARTINS, 1975, 1997; COSTA, 2000).

Nesse processo de expropriação e violência, a Igreja e a Comissão Pastoral da Terra (CPT) foram as principais instituições a lutar a favor dos colonos e contra o processo de grilagem de terra na região. Em fevereiro de 1980, foi divulgado o relatório "Igreja e os problemas da Terra" pela Conferência Nacional dos Bispos do Brasil (CNBB). Neste documento, a Igreja condena as políticas governamentais para o campo e denuncia a políticas de incentivos fiscais para a região (SOARES, 2009). 


\subsubsection{Fontes de Dados}

Para este trabalho, foram utilizadas publicações do IBGE, Ipeadata, Atlas do Desenvolvimento Humano, Firjan, PNUD e da Seplan-TO. Os indicadores utilizados foram: população urbana e rural, taxa de urbanização, densidade demográfica, mortalidade infantil, taxa de fecundidade, taxa de alfabetização, esperança de vida ao nascer, índice de Theil-renda, Índice Firjan, renda domiciliar per capita, taxa de pobreza, taxa de pobreza extrema, bolsa família para o Brasil, Tocantins e para Microrregião do Bico do Papagaio.

\section{ALGUMAS CONSIDERAÇÕES SOBRE A METODOLOGIA DOS INDICADORES.}

O índice de Theil-renda mede o grau de desigualdade na distribuição da renda domiciliar per capita entre os indivíduos (Pnad/IBGE, 2010).

O Índice Firjan (2010) de Desenvolvimento Municipal é um estudo que acompanha o desenvolvimento de mais de cinco mil municípios brasileiros nas áreas de Emprego, Renda, Educação e Saúde. Este índice varia de 0 a 1, e quanto mais próximo de 1 maior o desenvolvimento do município. Está classificado em quatro faixas: i) Baixo desenvolvimento (inferior a 0,4); ii) Desenvolvimento regular (entre 0,4 e 06); iii) Desenvolvimento moderado (entre 0,6 e 08,); e iv) Alto desenvolvimento (superior a 0,8 pontos).

A taxa de pobreza constitui o percentual de pessoas na população total com renda domiciliar per capita inferior à linha de pobreza. A linha de pobreza aqui considerada é o dobro da linha de extrema pobreza (Pnad/IBGE, 2010).

Por fim, o Bolsa Família, programa de transferência de renda com condicionalidades, que beneficia famílias em situação de pobreza e de extrema pobreza em todo o país. Este programa integra o Plano Brasil sem Miséria, que tem como foco de atuação os 16 milhões de brasileiros com renda familiar per capita inferior a $\mathrm{R} \$ 70,00$ mensais, e tem por base a garantia de renda, inclusão produtiva e acesso aos serviços públicos. Resultante da unificação de diferentes programas, ele foi instituído por lei em 2004. O Valor do benefício, reajustável por decreto, varia conforme o número e a idade dos filhos (MDS, 2010).

\section{RESULTADOS E DISCUSÕES}

\subsection{Indicadores sociais, humanos e econômicos da região do Bico do Papagaio}


A seguir, serão apresentados e discutidos alguns indicadores sociais, populacionais e econômicos do Brasil, Tocantins e da Microrregião. Optou-se pela agregação dos 25 municípios que compõem a Microrregião do Bico do Papagaio. O objetivo é fazer uma breve comparação da sua evolução, ficando claro, desde já, que a transferência de renda do Governo Federal, via Bolsa Família, vem contribuindo para a redução da miséria nessa Microrregião. A análise será feita pela média simples de alguns indicadores e pela taxa de variação acumulada entre 2000 e 2010. Todos os indicadores aqui apresentados são derivados da Tabela 1.

A população da Microrregião era de 174.224 habitantes em 2000, dos quais, 63.231 viviam no meio rural, o que corresponde a $36 \%$ do total. Em 2010, a população passou para 196.3671, e a rural, para 66.516, o que corresponde a 33,85\% do total. A análise da taxa de variação acumulada da população rural desta Microrregião cresceu 5,20\% em 2010, enquanto a população rural do Estado do Tocantins teve um decréscimo de -1,28\%, seguindo a tendência do Brasil que foi de $-6,33 \%$, ou seja, enquanto Brasil e Tocantins apresentaram uma queda de sua população rural, a Microrregião do Bico do Papagaio foi na contramão.

Por outro lado, observa-se o fenômeno da urbanização, na Microrregião, no Tocantins como no Brasil, com $66 \%, 79 \%$ e $84 \%$, respectivamente, de sua população residindo na zona urbana em 2010 (Tabela 1).

Analisando a Taxa de Mortalidade por mil nascidos vivo, tanto na Microrregião, no Tocantins como no Brasil, observa-se queda neste indicador, -16,6\%, -14,4\% e -26,4\%, respectivamente, podendo-se inferir que esta redução pode estar relacionada com a melhoria na renda e nas políticas públicas implementadas pelo Governo Federal, como o Bolsa Família, que condiciona o recebimento do benefício à matrícula dos filhos na escola, à apresentação da carteirinha de vacinação dos filhos e ao acompanhamento à gestantes.

A Microrregião apresentou a maior taxa de fecundidade, 2,71, em 2010, entre os três entes federativos analisados. Tocantins apresentou uma taxa de 2,60 e Brasil, 1,94. No entanto, entre 2000 e 2010, houve redução nas três unidades federativas: a Microrregião apresentou a maior redução, -28,12\%; Tocantins, redução de -11,26\%; e Brasil, redução de $-18,49 \%$. 
Tabela 1 - Indicadores Sociais, Populacionais e econômicos do Brasil, Tocantins e da Microrregião do Bico do Papagaio - 2000 e 2010.

Table 1 - Social Indicators Population and economic Brazil, Tocantins and the Microregion of the Bico do Papagaio - 2000 and 2010 .

\begin{tabular}{|c|c|c|c|c|c|c|c|c|c|}
\hline \multirow{2}{*}{$\begin{array}{c}\text { Indicadores } \\
\text { Socioeconômicos }\end{array}$} & \multicolumn{3}{|c|}{ Brasil } & \multicolumn{3}{|c|}{ Tocantins } & \multicolumn{3}{|c|}{ Microrregião B. do Papagaio } \\
\hline & 2000 & 2010 & $\Delta \%$ & 2000 & 2010 & $\Delta \%$ & 2000 & 2010 & $\Delta \%$ \\
\hline População Total (mil hab) & 169.799 & 190.732 & 12,33 & 1.157 & 1.383 & 19,56 & 174 & 196 & 12,71 \\
\hline População Urbana (mil hab) & 137.953 & 160.952 & 16,67 & 859 & 1.090 & 26,76 & 110 & 129 & 16,99 \\
\hline População Rural (mil hab) & 31.845 & 29.830 & $-6,33$ & 297 & 293 & $-1,28$ & 63 & 66 & 5,20 \\
\hline Taxa de Urbanização (\%) & 81,00 & 84,00 & 3,70 & 74,00 & 79,00 & 6,76 & 63,00 & 66,00 & 4,76 \\
\hline Densidade Demográfica & 19,94 & 22,40 & 12,34 & 4,15 & 4,98 & 20,00 & 11,05 & 12,45 & 12,67 \\
\hline Mortalidade Infantil & 30,57 & 22,50 & $-26,40$ & 29,93 & 25,60 & - 14,47 & 61,80 & 51,50 & 16,67 \\
\hline Taxa de Fecundidade (\%) & 2,38 & 1,94 & $-18,49$ & 2,93 & 2,60 & - 11,26 & 3,77 & 2,71 & 28,12 \\
\hline Taxa de Alfabetização (\%) & 87,60 & 90,30 & 3,08 & 78,84 & 86,50 & 9,72 & 71,80 & 78,90 & 9,89 \\
\hline Esperança de vida ao nascer & 70,55 & 73,20 & 3,76 & 69,20 & 71,90 & 3,90 & 60,55 & 66,50 & 9,83 \\
\hline Índice Theil -renda & 0,72 & 0,52 & - 27,78 & 0,67 & 0,51 & $-23,88$ & 0,53 & 0,49 & 7,55 \\
\hline IFDM & 0,59 & 0,78 & 32,20 & 0,49 & 0,68 & 38,78 & 0,47 & 0,56 & 19,15 \\
\hline Renda Domiciliar per capta & 563,49 & 705,00 & 25,11 & 307,10 & 571,00 & 85,93 & 304,50 & 395,50 & 29,89 \\
\hline Taxa de Pobreza & 35,17 & 21,42 & - 39,10 & 50,61 & 26,09 & $-48,45$ & 81,39 & 73,79 & 9,34 \\
\hline Taxa de Pobreza Extrema & 15,28 & 7,28 & $-52,36$ & 22,13 & 8,16 & $-63,13$ & 47,98 & 29,50 & 38,52 \\
\hline Bols a Família (mil) & 439.870 & 1.239 .000 & 181,67 & 8.803 & 12.366 & 40,47 & 931 & 2.724 & 192,58 \\
\hline
\end{tabular}

Fontes: IBGE - Censo Demográfico (2000, 2010); Ipeadata (2000, 2010); Atlas do Desenvolvimento; Ipeadata (2000 e 2010); SEPLAN-TO (2010); Pnad/IBGE (2000 e 2010).

Para Taxa de Alfabetização, a Microrregião tem apresentado melhoria nesse indicador: em 2000, a taxa de alfabetização era de $71,8 \%$, tendo passado para 78,9\% em 2010, um crescimento no período de 9,89\%; no Tocantins, em $2010,86,5 \%$ da população estava alfabetizada contra 90,3\% do País. Mais uma vez, pode-se inferir que essa melhoria na redução do analfabetismo é oriunda de políticas educacionais implementadas no país, como o ProUni, ENEN e EJA. ${ }^{6}$

${ }^{6}$ ProUni é um programa do Ministério da Educação, criado pelo Governo Federal em 2004, que oferece bolsas de estudos em instituições de educação superior privadas, em cursos de graduação e seqüenciais de formação específica, a estudantes brasileiros, sem diploma de nível superior. (Brasil, 2004)

ENEM: Exame Nacional do Ensino Médio - foi criado pelo MEC (Ministério da Educação e Cultura) no ano de 1998. Este sistema de avaliação tem por objetivo avaliar os estudantes de escolas públicas e particulares do Ensino Médio. Os dados, além de servirem de base para o desempenho pessoal, também são utilizados pelo governo para definir políticas públicas educacionais. A partir de 2010 as universidades públicas e privadas estão utilizando os resultados do ENEM dentro de seus sistemas de seleção.

EJA: Educação de Jovens e Adultos - tem como objetivo de restaurar o direito à educação negado aos jovens e adultos, oferecendo a eles igualdade de oportunidades para a entrada e permanência no mercado de trabalho e qualificação para uma educação permanente Jovens e Adultos com idade de 15 a 80 anos, ou mais. A maioria são trabalhadores, adultos, com experiência profissional ou com expectativa de inserção no mercado de trabalho. 
Analisando a esperança de vida ao nascer, constata-se que a Microrregião apresentou melhorias significativas nesse indicador em 2000. Ele era de 60,55, tendo passado para 66,50 anos em 2010, apresentando um crescimento no período de 9,83\%. Para o Estado do Tocantins, a expectativa passou de 69,20 em 2000 para 71,90 em 2010; para Brasil, a expectativa, que era de 70,55, passou para 73,20 anos.

Para a análise de desigualdade de renda, optou-se pelo índice Theil-renda, que mede o grau de desigualdade na distribuição da renda domiciliar per capita entre os indivíduos. A Microrregião apresentou a menor desigualdade, 0,49, Tocantins, 0,51, e Brasil apresentou 0,52 em 2010. Como já mencionado, esse índice varia de 0 a 1: quanto mais próximo de um, maior a concentração, e quanto mais próximo de zero, menor a concentração de renda. Esse índice se reduziu em 27,7\% no Brasil, em 23,8\% no Tocantins e em 7,55\% na Microrregião em estudo (Tabela 1).

A Microrregião apresentou em 2000 um Índice Firjan de Desenvolvimento Municipal (IFDM) de 0,47, Tocantins, 0,49, e Brasil, de 0,59, todos na faixa regular, segundo a metodologia da Firjan. Para o ano de 2010, esse índice passou a ser considerado moderado para Brasil $(0,78)$ e Tocantins $(0,68)$, permanecendo a Microrregião na faixa de regular, com 0,56. Observa-se que houve melhoria em todos os entes federativos. E esse indicador contempla as áreas de emprego-renda, educação e saúde.

Como se pode constatar, o Brasil vem apresentando melhoria na renda nas últimas décadas (2000 e 2010). A renda domiciliar per capita no Brasil, que era de $\mathrm{R} \$ 563,49$ em 2000, passou para $\mathrm{R} \$ 705,00$ em 2010 , um aumento de $25 \%$ no período (valores corrido). No Tocantins e na Microrregião, a renda domiciliar per capita em 2000 era de $\mathrm{R} \$ 307,00$ e $\mathrm{R} \$ 304,00$, em 2010, ela passou para $\mathrm{R} \$ 571,00$ e $\mathrm{R} \$ 395,00$, respectivamente. O Tocantins apresentou o maior crescimento da renda, cerca de $86 \%$ no período em análise.

A taxa de pobreza na Microrregião do Bico do Papagaio é elevada. Em 2000, era de $81,39 \%$, em 2010 , era de $74 \%$, isto é, mais de quase $75 \%$ da população vivia com valor de uma cesta de alimentos com o mínimo de calorias necessárias para suprir adequadamente uma pessoa, com base em recomendações da Organização das Nações Unidas para Alimentação e Agricultura (FAO) e da Organização Mundial de Saúde (OMS) (Ipeadata, 2000). No Tocantins, houve queda de mais de $-48 \%$ na taxa de pobreza: em 2000, ela era de 50,61, em 2010, se reduziu para 26,09. No Brasil, essa queda foi de $-39 \%$. 
Houve também no País redução da taxa de pobreza extrema no período em análise (2000 e 2010). No Brasil, ela se reduziu em cerca de 52\%; em 63\%, no Tocantins; e em 38\%, na Microrregião do Bico do Papagaio. Segundo Ipea (2000), a linha de extrema pobreza no Brasil é de R\$ 70,00 per capita ao mês, utilizada pelo Programa Bolsa Família no Brasil, bem próxima do U\$ 1,25 ao dia adotado pelo Banco Mundial.

Por fim, o Programa Bolsa Família, instituído no País em 2004, tem gerado controvérsias na sociedade quanto à sua eficácia: para alguns, ele tem impulsionado a economia local no interior do País; para outros, o Programa é de cunho eleitoreiro. Não cabe aqui discutir a validade ou não do Programa. A Tabela 1 mostra o repasse para o Programa de 2004 a 2010, que aumentou 181\% para o Brasil, 40\% para o Tocantins e mais de $190 \%$ para a Microrregião do Bico do Papagaio. Cabe ressaltar aqui que esta Microrregião é a que mais recebe benefícios do Programa Bolsa Família no Estado do Tocantins (IPEADATA, 2010).

\section{CONSIDERAÇÕES FINAIS}

O presente artigo tem por objetivo caracterizar a pobreza e os indicadores de desenvolvimento humano, social e econômico numa região periférica do Estado do Tocantins: a Microrregião do Bico do Papagaio. Trata-se de uma região de extrema pobreza, com grandes desigualdades sociais e econômicas e, para completar, foi palco de enormes conflitos agrários nas décadas de 1970 e 1980. No Tocantins, a pobreza é extrema, o estado tem um dos piores indicadores socioeconômicos do país. E esse problema persiste de forma secular.

Como mostrou o IBGE (2010), o Brasil tem 16,2 milhões de brasileiros que vivem em extrema pobreza, o equivalente a $8,5 \%$ da população. No Tocantins, esse percentual chega a $11,8 \%$ da sua população vivendo em extrema pobreza, cerca de 163 mil de um total de 1.383,4 mil habitantes

A Abordagem da Capacitação (AC) foi o referencial teórico adotado neste trabalho, que ajudou compreender que a pobreza é multidimensional. A perspectiva dessa abordagem não se restringe apenas à análise da pobreza, trazendo contribuições importantes para a Teoria do Bem-Estar Social e para a Teoria do Desenvolvimento Socioeconômico, particularmente, porque analisa o desenvolvimento a partir do princípio da igualdade e da liberdade substantiva. O bem-estar da sociedade deve ser avaliado segundo as liberdades desfrutadas 
por seus membros. A liberdade é o determinante principal da iniciativa individual e da eficácia social.

A liberdade é o fim primordial e o principal meio do desenvolvimento. E entre essas liberdades, estão: liberdade política, facilidade econômica, oportunidades sociais, garantias de transparência e segurança protetora. $\mathrm{Na} \mathrm{AC}$, a pobreza deve ser entendida como a privação de capacitações básicas. Essa abordagem está relacionada com o conceito de desenvolvimento humano.

Dessa forma, algumas considerações são atinentes. A população rural da Microrregião correspondia a 33,85\% do total em 2010. O fenômeno de urbanização ocorreu tanto na Microrregião quanto no Tocantins e no Brasil. A Microrregião apresentou queda na mortalidade infantil, por outro lado, tem a maior taxa de fecundidade em 2010 entre os três entes federativos analisados. A Taxa de Alfabetização foi reduzida, podendo-se inferir que essa melhoria na redução do analfabetismo é oriunda de políticas educacionais implementadas no país, como o ProUni, ENEN e EJA.

Analisando a esperança de vida ao nascer, constata-se que a Microrregião apresentou melhorias significativas nesse indicador em 2000, que era 60,55 e passou para 66,50 anos em 2010. A Microrregião apresentou a menor desigualdade de renda, 0,49; Tocantins, 0,51; e Brasil, 0,52, em 2010. Esse índice se reduziu para 27,7\% no Brasil, 23,8\% no Tocantins e 7,55\% na Microrregião em estudo. A Microrregião apresentou, em 2000, Índice Firjan de Desenvolvimento Municipal (IFDM) de 0,47; Tocantins, de 0,49; e Brasil, de 0,59. Todos na faixa regular, segundo a metodologia da Firjan. Para o ano de 2010, esse índice passou a ser considerado moderado para Brasil $(0,78)$ e Tocantins $(0,68)$, permanecendo a Microrregião na faixa de regular $(0,56)$. Esse indicador contempla as áreas de emprego-renda, educação e saúde. Como se pode constatar, o Brasil vem apresentando melhoria na renda nas últimas décadas. A renda na Microrregião domiciliar per capita, em 2000, era de $\mathrm{R} \$ 304,00$, em 2010, passou para $\mathrm{R} \$ 395,00$.

A taxa de pobreza na Microrregião do Bico do Papagaio é elevada. Em 2000, era de $81,39 \%$, em 2010 , era de $74 \%$, isto é, mais de quase $75 \%$ da população vivia com valor de uma cesta de alimentos com o mínimo de calorias necessárias para suprir adequadamente uma pessoa, com base em recomendações das Organizações das Nações Unidas para Alimentação e Agricultura (FAO) e da Organização Mundial de Saúde (OMS). 
Houve também redução da taxa de pobreza extrema, no período em análise (2000 e 2010), de 38\%, na Microrregião do Bico do Papagaio. Por fim, o Programa Bolsa Família instituído no País em 2004, aumentou em mais de 190\% para a Microrregião do Bico do Papagaio. Cabe ressaltar aqui que esta Microrregião é a que mais recebe benefícios do Programa Bolsa Família no Estado do Tocantins.

Os dados apresentados permitem observar que a Microrregião do Bico do Papagaio tem posição mediana a regular em termos de desenvolvimento socioeconômico. Houve melhorias em alguns indicadores, mas ainda há muito que avançar para chegar a um padrão satisfatório de desenvolvimento social e econômico.

Aceita-se a hipótese de que a abordagem multidimensional para analisar a pobreza e os diversos indicadores humanos, sociais e econômicos, tanto do Tocantins como da Microrregião do Bico do Papagaio, foi adequada para compreender a trajetória dessa região, a qual é resultado histórico do processo de desenvolvimento capitalista brasileiro, bem como da expansão da fronteira agrícola na Amazônia, que não é um espaço isolado, mas sim parte integrante e interdependente da economia capitalista. Pode-se inferir que os gestores da Microrregião, o poder público estadual e federal vêm, de forma ainda limitada, investindo na qualidade de vida da sua população.

Este trabalho não esgota o assunto aqui tratado, recomendando-se que seja feito para outras regiões do estado e do País, utilizando outras metodologias.

\section{REFERÊNCIAS}

ABREU, M. P. (Org). A Ordem do progresso. Rio de Janeiro: Campus, 1990.

ARAGÓN, Luis E. Mobilidade Geográfica e Ocupacional do Norte de Goiás: um exemplo de migrações por sobrevivências. Cadernos NAEA. Belém: Universidade do Pará, no 6: 89-105, 1981.

BRASIL, Ministério da Educação (MEC). ProUni - Programa Universidade para todos. Brasília: 2004. Disponível: 〈http://www.mec.gov.br> acesso em 01 de julho de 2013.

BRASIL, Ministério do Desenvolvimento Social e Combate à Fome (MDS). Programa Bolsa Família. Brasília: 2010. Disponível: <http://www.mds.gov.br> acesso em 02 de julho de 2013.

CODES, A. L. M. A Trajetória do Pensamento Científico sobre Pobreza: em direção a uma visão complexa. Texto para discussão. Rio de Janeiro: IPEA, n. 1332, abr. 2008

COMIM, F,; BAGOLIN, I. P.; AVILA, R.; PORTO JUNIOR, S. S.; PICOLOTTO, V.C. Pobreza: da insuficiência de renda à privação de capacitações - uma aplicação para a cidade de Porto Alegre através de um indicador multidimensional. Projeto de Pesquisa. Faculdade de Ciências Econômicas, Universidade Federal do Rio grande do Sul. UFGRS, Porto Alegre, 2009 
COSTA, F. A. Formação agropecuária da Amazônia: os desafios do desenvolvimento sustentável, Belém - PA UFPA/NAEA, 2000. 350p.

FIRJAN - Federação das Indústrias do Estado do Rio de Janeiro. Índice FIRJAN de Desenvolvimento Municipal (IFDM), 2010. Disponível em <www.firjan.org.br/ifdm>, acessado em 20 de fevereiro de 2013.

INSTITUTO BRASILEIRO DE GEOGRAFIA E ESTATÍSTICA - IBGE. Censo Populacional, 2000 e 2010. Disponível em <http://www.ibge.gov.br> acesso em 30 de junho de 2013.

LACERDA, F. C. C. A Pobreza na Bahia sob o prisma multidimensional: uma análise baseada na abordagem das necessidades básicas e na abordagem das capacitações. $210 \mathrm{f}$. Dissertação (Mestrado em Economia) - Instituto de Economia, Universidade Federal de Uberlândia, UFU, Uberlândia, 2009.

MACHADO, K. Mensuração da Pobreza: uma comparação entre a renda e a abordagem multidimensional. 125f. Dissertação (Mestrado em Administração). Escola de Administração, Universidade Federal da Bahia, salvador, 2006.

MARTINS, J. S., Exploração e violência. São Paulo, Hucites, 1975.

MARTINS, José de Souza. Fronteira: a degradação do outro nos confins do humano. São Paulo: Hucitec, 1997.

PNUD - Programa das Nações Unidas para o Desenvolvimento. Relatório do Desenvolvimento Humano $(R D H), \quad 2011 . \quad$ Disponível em $<$ http://hdrstats.undp.org/en/indicators/103106.html> acessado em 27 de janeiro de 2013.

ROCHA, S. Pobreza no Brasil: afinal de que se trata? Rio de Janeiro: FVG, 2003.

SALAMA, P.; DESTREMAU, B. O Tamanho da Pobreza: economia política da distribuição de renda. Rio de janeiro: Garamound, 1999.

SEN, A.Desenvolvimento como liberdade. São Paulo: Companhia das Letras, 2000. 409p.

SEN, A. Desigualdade Reexaminada. Rio de Janeiro: Record, 2008a.

SEN, A. Entrevista - Amartya Sen (entrevistadora Mônica Teixeira). Memória Roda Viva.

FAPESP. 2001. Disponível em < http:// www.rodavia.fapes.br> acesso em 25 de agosto de 2013.

SEN, A. Ética e economia. São Paulo: Companhia das letras, 2008b.

SEN, A. Poverty and Famines: an essay on entitlemente and deprivation. Oxford: Oxford University Press, 1983. Cap. 1 e 2

SOARES, Zaré, A. B. Agricultura Familiar, Movimentos Sociais e Desenvolvimento Rural na Região do Bico do Papagaio - Tocantins: um estudo sobre as relações entre sociedade civil e desenvolvimento. 250 f. (Mestrado em Desenvolvimento Sociedade e Agricultura), Universidade Federal Rural do Rio de Janeiro. Seropédica, 2009.

\section{Nilton Marques de Oliveira}

Doutorando em Desenvolvimento Regional e Agronegócio pela Universidade Estadual do Oeste do Paraná - UNIOESTE, Toledo - PR. Graduado em Ciências Econômicas pela Universidade Estadual de Maringá - UEM. Mestre em Economia Aplicada pela Universidade Federal de Viçosa - UFV. Professor de economia da Universidade Federal do Tocantins UFT, desde 2008. Pesquisador dos Grupos de Estudos em Economia Aplicada e Interdisciplinar de Estudos e Pesquisa sobre Estado, Educação e Sociedade (Geipees) da UFT. Coordenador do Curso de Ciências Contábeis da União do Ensino Superior de Nova Mutum Uninova, no período de 1997 a 1999. Diretor de Pesquisa da União do Ensino Superior de Nova Mutum - Uninova, de 1999 a 2000. Coordenador de Curso do Centro Universitário de Desenvolvimento do Centro Oeste - Unidesc de 2003 a 2005. Coordenador da Comissão 
Própria de Avaliação (CPA) da Faculdade Jesus Maria José - FAJESU de 2005 a 2008. Diretor de Avaliação da Pró-Reitoria de Avaliação e Planejamento - PROAP/UFT de 2008 a 2012. Área de Pesquisa: Desenvolvimento Regional, com ênfase em economia regional e urbana, pobreza, desigualdades, análise regional e Economia do Tocantins. Possui diversos artigos e textos publicados em eventos e periódicos nacionais e internacionais.

E-mail: niltonmarquesuft@gmail.com

Endereço: Universidade Federal do Tocantins - Quadra 109 Norte Av. NS-15, ALCNO-14. Plano Diretor Norte. CEP: 77001-090. Palmas/TO

\section{Udo Strassburg}

Doutorando em Desenvolvimento Regional e Agronegócio na UNIOESTE - Toledo, mestre em Controladoria e Contabilidade Estratégica pela FACESP/FECAP - Fundação Álvares Penteado, em São Paulo, em 2001. Cursou Especialização em Controladoria e Gerência Financeira na UNIOESTE, em 1998 e Graduou-se em Ciências Contábeis na UNIOESTE/FECIVEL, em 1984-1987. Atualmente é professor assistente 4 da UNIOESTE Universidade Estadual do Oeste do Paraná, em Cascavel.

E-mail: udo.strassburg@unioeste.br

Endereço: Universidade Estadual do Oeste do Paraná R. Universitária, 1619 - Universitário Cascavel - PR - Brasil - CEP: 85819-110 